Gcorge A Arndt MD,

Tim Gerry MD,

Patricia White CRNA

\section{Postoperative reparalysis after rocuronium following nebulized epinephrine}

Purpose: We report a case of postoperative reparalysis in the recovery room, following nebulized epinephrine. The patient was pharmacologically reversed with edrophonium after paralysis with rocuronium.

Clinical findings: A 12-yr-old girl developed postoperative reparalysis following the intraoperative administration of rocuronium. A total of $0.92 \mathrm{mg} \cdot \mathrm{kg}^{-1}$ rocuronium was administered. After surgery, pharmacological reversal was achieved with $20 \mathrm{mg}$ edrophonium with $0.15 \mathrm{mg}$. atropine sulfate iv 35 min after the last administration of rocuronium. Muscular relaxation was monitored using an ulnar peripheral nerve stimulator (PNS). After reversal, a full train-of-four and sustained tetanus at $50 \mathrm{~Hz}$ were present. In the recovery room, following nebulized epinephrine, the patient became apneic. The patient was paralyzed and an ulnar PNS demonstrated only one faint twitch. The paralysis was reversed with $1.5 \mathrm{mg}$ neostigmine with $0.3 \mathrm{mg}$ glycopyrrolate.

Conclusion: Postoperative reparalysis following rocuronium may be a cause of postoperative respiratory distress. The definitive diagnosis is made using PNS and observing the response to pharmacological reversal. Nebulized epinephrine may have a previously undescribed role in the development of postoperative reparalysis.

Objectif : Les auteurs décrivent un cas de recurarisation survenue en salle de réveil à la suite d'une nébulisation d'épinéphrine. La curarisation produite par le rocuronium avait été neutralisée par l'administration d'édrophonium.

Éléments cliniques : Une fillette de 12 ans s'est recurarisée à la période postopératoire malgré l'administration peropératoire d'édrophonium. Elle avait reçu une dose totale de $0.92 \mathrm{mg} \cdot \mathrm{kg}^{\prime}$ de rocuronium. Après l'intervention, la décurarisation pharmacologique était effectuée avec $20 \mathrm{mg}$ d'édrophonium et $0.15 \mathrm{mg}$ de sulfate d'atropine iv administrés $35 \mathrm{~min}$ après la dose de rocuronium. La relaxation était monitorée au nerf cubital à l'aide d'un stimulateur nerveux périphérique (SNP). Après la neutralisation, on constatait un retour complet du trainde-quatre et un tétanos soutenu à $50 \mathrm{~Hz}$. À la salle de réveil, la patiente devenait apnéique après une nébulisation d'épinéphrine. La paralysie était renversée par $1.5 \mathrm{mg}$ de néostigmine et $0.3 \mathrm{mg}$ de glycopyrrolate.

Conclusion : Une recurarisation postopératoire après l'administration de rocuronium peut provoquer de la détresse respiratoire. Le diagnostic se fait avec un SNP et l'observation de la réponse pharmacologique. L'épinéphrine en nébulisation pourrait jouer un rôle jusqu'à maintenant ignoré dans l'apparition de la recurarisation.

From the Department of Anesthesiology, University of Wisconsin Clinical Science Center, B6/319 CSC, 600 Highland Avenue, Madison, WI $53792-3272$.

Address correspondence to: Dr. George Arndr. Phone: (608) 263-8100; Fax: (608) 263-0575.

Accepted for publication November $30,1996$. 
$\mathrm{R}$

OCURONIUM was recently introduced into clinical practice in North America. We report a case of postoperative reparalysis following pharmacological reversal with edrophonium. Rocuronium has a rapid onset of action with minimal cardiovascular side effects. ${ }^{1,2}$ Rocuronium is a low potency monoquaternary steroidal muscle relaxant chemically related to vecuronium. It has an $\mathrm{ED}_{95}$ of $300 \mu \mathrm{g} \cdot \mathrm{kg}^{-1}$ and has a considerably faster onset than either atracurium or vecuronium..$^{3,5}$

Nondepolarizing muscle relaxants have the inherent risk of postoperative weakness and respiratory compromise. ${ }^{13,14}$ The aetiology of postoperative respiratory compromise is multifactorial. In cases of reparalysis, postoperative weakness may be detected using PNS. ${ }^{13}$ This case is unique as the reparalysis occurred after nebulized epinephrine following edrophonium reversal after rocuronium administration. Before tracheal extubation, clinical reversal was achieved and documented by achieving a sustained response to train-of-four and $50 \mathrm{~Hz}$ tetanic stimulation. In the recovery room, reparalysis was diagnosed using PNS.

In the postoperative patient, there are many causes of ventilatory compromise. In a patient reparalyzed from a neuromuscular blocker, the diagnosis can be made using a peripheral nerve stimulator. Rocuronium may be a possible cause of postoperative weakness and reparalysis.

\section{Case Report}

A 12-yr-old, 28-kg patient was scheduled for elective rigid bronchoscopy to evaluate oral-tracheal candidiasis and to have a central venous line placed. The past medical history was remarkable for a recurrent astrocytoma, neurofibromatosis, oral-tracheal candidiasis and pancytopenia. She had received chemotherapy and radiation therapy one year before admission. Preoperative medication included acyclovir, cytrabine, allopurinol, amoxicillin, dexamethasone, fluconazole, immunoglobin, ranitidine, and trimethoprim/sulfamethoxazole. Preoperative laboratory tests showed a haemoglobin concentration of $8.4 \mathrm{~g} \cdot \mathrm{dl}^{-1}$ and a white blood cell count of $400 \mathrm{~K} \cdot \mathrm{ml}^{-1}$. Physical examination revealed oral candidiasis. Routine monitors including ECG monitoring lead II, pulse oximeter, and an automated blood pressure cuff were placed before induction of anaesthesia. Intraoperatively, temperature, end-tidal inhalational agent concentration and capnography were monitored. She was premedicated with 500 $\mu \mathrm{g}$ alfentanil and $0.5 \mathrm{mg}$ midazolam ip. Anaesthesia was induced with $12 \mathrm{mg}$ etomidate $i v$, and maintained with halothane $0.78 \%$ end-tidal in nitrous oxide $70 \%$ and oxygen. Rocuronium, $20 \mathrm{mg} i v, 0.7 \mathrm{mg} \cdot \mathrm{kg}^{-1}$, was administrated for introduction of a rigid bronchoscope. During the bronchoscopy, $100 \mu \mathrm{g} \cdot \mathrm{kg}^{-1} \cdot \mathrm{min}^{-1}$ propofol $i v$ and oxygen $100 \%$ were used. Following bronchoscopy, the trachea was intubated, and an additional $6 \mathrm{mg}, 0.21 \mathrm{mg}^{\mathrm{kg}}{ }^{-1}$, rocuronium were required. A subclavian central venous line was inserted. The post insertion roentgenogram was normal and the intraoperative course was unremarkable: The vital signs were stable. At the end of the case, the patient had two twitches in response to train-of-four PNS. A left ulnar PNS was used with surface electrodes. The PNS was adjusted to deliver a supramaximal stimulus before rocuronium was administered. Neuromuscular blockade was reversed with $20 \mathrm{mg}$ edrophonium and 0.15 mg atropine $i v, 35 \mathrm{~min}$ after the last dose of rocuronium. Neuromuscular function returned in approximately seven minutes. Ulnar PNS revealed four twitches of equal height consistent with the four baseline twitches. Five second sustained tetanus at $50 \mathrm{~Hz}$ was also present. Prior to extubation, the patient was breathing spontaneously with a respiratory rate of $16 \mathrm{bpm}$. The $\mathrm{P}_{\mathrm{ET}} \mathrm{CO}_{2}$ was $40 \mathrm{mmHg}$ and $\mathrm{SpO}_{2}$, was $100 \%$. The trachea was extubated after the patient was able to follow verbal commands. Oxygen was administered using a $40 \%$ face mask. She was taken to the recovery area. The case lasted $91 \mathrm{~min}$.

On arrival in the recovery room, the patient was alert and able to follow commands. Vital signs revealed a pulse of 120 , respiratory rate of $16 \mathrm{bpm}$, blood pressure of $95 / 56 \mathrm{mmHg}$ and $\mathrm{SpO}_{2}$ of $95 \%$. Because of mild bronchoscopic airway trauma, $0.3 \mathrm{ml}$ racemic epinephrine in $3 \mathrm{ml}$ normal saline was started using a nebulizer. The pulse immediately increased to $145 \mathrm{bpm}$ and the blood pressure to $115 / 65 \mathrm{mmHg}$. Approximately 15 min after starting epinephrine, over five minutes, the patient became unresponsive. The respiratory effort became shallow and progressed to apnea. The $\mathrm{SpO}_{2}$, decreased to $50 \%$. The pulse was $145 \mathrm{bpm}$ and blood pressure 110/65 mm $\mathrm{Hg}$. A bag and mask airway was quickly secured and the lungs were ventilated with $100 \%$ oxygen. The $\mathrm{SpO}_{2}$, increased rapidly to $100 \%$. Epinephrine was discontinued, the pulse decreased to $115 \mathrm{bpm}$ and blood pressure remained unchanged. Gross physical examination demonstrated no major postoperative physical changes. The airway was open, heart tones normal, and rhonchi were heard which were present preparatively. No other drugs were administered other than nebulized racemic epinephrine. In the course of elucidating the problem, a left ulnar PNS was placed using surface electrodes. A supramaximal train-of-four was delivered and only one slight twitch was present. Neostigmine, $1.5 \mathrm{mg} i v$ with $0.3 \mathrm{mg}$ glycopyrrolate was administered. Over the next $10 \mathrm{~min}$, there was return of 
neuromuscular function as indicated by a full response to train-of-four stimulation and sustained tetanus at $\mathbf{5 0}$ $\mathrm{Hz}$. The patient became responsive and alert.

\section{Discussion}

Clinical practice is undergoing transition with the introduction of two new muscle relaxants, rocuronium and cisatracurium. Both vecuronium and atracurium, in widespread clinical use, are near to ideal muscle relaxants. ${ }^{1}$ The newer muscle relaxants, however, offer some clinical advantages. ${ }^{2,3}$ The use of rocuronium in paediatric patients is well described.,

This patient reparalyzed in the recovery room, rocuronium and epinephrine may have contributed. Only nebulized racemic epinephrine was administered after which the patient became weak and quickly progressed to apnea with $\mathrm{SpO}_{2}$ of $50 \%$. Reparalysis was diagnosed using a left ulnar PNS which showed only one faint twitch to TOF stimulation, and was confirmed by the response to neostigmine. Epinephrine has potent cardiovascular effects, increasing both cardiac output and blood pressure. The clinical course and temporal relationship between re-paralysis and the use of epinephrine suggests a relationship. The mechanism, however, is uncertain. Edrophonium is actively removed by the kidney using an active transport system $^{7}$ and its clearance may have been increased.

Rocuronium has a pharmacokinetic profile different from either vecuronium or atracurium. $1,3,6$ Although mean recovery times, at equipotent doses, of rocuronium are similar, rocuronium shows prolonged recovery after repeated doses or an accumulative effect. ${ }^{6}$ The clinical implication of this accumulative effect is uncertain. Neostigmine has been studied at doses between 30 and $80 \mu \mathrm{g} \cdot \mathrm{kg}^{-1}$ for reversal of rocuronium. A neostigmine dose of $\mathbf{8 0}$ $\mu \mathrm{g} \cdot \mathrm{kg}^{-1}$ is more effective than $30 \mu \mathrm{g} \cdot \mathrm{kg}^{-1}$ in reversing a deep level of paralysis. Based on the literature, neostigmine $80 \mu \mathrm{g} \cdot \mathrm{kg}^{-1}$ may have been a better clinical choice than edrophonium. The kinetics of rocuronium are altered by liver and renal disease, $, 8,10,11$ although in this patient there was no clinical or laboratory evidence of altered renal or hepatic function.

The development of reparalysis occurred shortly after beginning nebulized epinephrine. Return of neuromuscular function coincided with two events; discontinuation of nebulized epinephrine and administration of neostigmine $i$. From the clinical course and temporal association between paralysis and the recovery of neuromuscular function, reparalysis may have followed inadequate reversal of deep neuromuscular blockade, or have been an effect of epinephrine on the neuromuscular junction. Clinically, the answer is uncertain, howev- er, the most important clinical factors were the analysis of the problem, and a rational course of therapy.

The adoption of a vigilant attitude toward patient monitoring in the recovery room cannot be over emphasized. Vecuronium and atracurium have familiar recovery profiles and have perhaps, unknowingly, allowed a less vigilant attitude to have been adopted. The pulse oximeter, by providing continuous audio and visual output of the patient's arterial saturation, allowed easy vigilance and may have averted a clinical disaster. Before adoption of pulse oximetry, postoperative weakness or death from the use of neuromuscular blockers was not uncommon. ${ }^{12-14}$ The PNS must be included in the list of equipment easily available in the recovery room to evaluate postoperative weakness.

\section{Conclusion}

This case demonstrated a case of postoperative reparalysis. The recovery profile of rocuronium and the use of nebulized epinephrine may have been contributory. As with all neuromuscular blockers, clinicians may be tempted to reverse deep rocuronium neuromuscular blockade and risk possible postoperative reparalysis. Rocuronium has an accumulative effect and this may have contributed to the reparalysis. Edrophonium has been shown to be less effective than neostigmine in reversing deep levels of rocuronium paralysis. ${ }^{15}$ Neostigmine may have been a better clinical choice. Although there are no reports implicating epinephrine in the development of reparalysis, the temporal association between the development of reparalysis and the recovery following its discontinuation raises clinical suspicions.

The adoption of a vigilant attitude toward postoperative monitoring cannot be over emphasized. Pulse oximetry averted a clinical catastrophe. In the midst of an emergency or hectic pace of a busy recovery room, it allows easy monitoring of $\mathrm{SpO}_{2}$ providing casily interpreted visual and audio data while allowing other tasks to be continued. In the postoperative patient, when apnea develops, reparalysis must be considered. Diagnosis is made easily with PNS which should be a standard part of all recovery room equipment.

\section{References}

I Booij LHDJ, Knape HTA. The neuromuscular blocking effect of ORG 9426. A new intermediately-acting steroidal non-depolarising muscle relaxant in man. Anaesthesia 1991; 46: 341-3.

2 Wierda JMKH, De Wit APM, Kuizenga $K$, Agoston S. Clinical observations on the neuromuscular blocking action of ORG 9426, a new steroidal non-depolarizing agent. Br J Anaesth 1990; 64: 521-3. 
3 Mirakbur RK, McCoy EP. The new relaxants. Current Opinion in Anaesthesiology 1994; 7: 365-9.

4 Woelfel SK, Brandom BW, Cook DR, Sarner JB. Effects of bolus administration of ORG-9426 in children during nitrous oxide - halothane anesthesia. Anesthesiology 1992; 76: 939-42.

5 O'Kelly B, Fiset P, Meistelman C, Ecoffey C.

Pharmacokinetics of rocuronium bromide in paediatric patients. Eur J Anaesthesiol 1994; 11(Suppl): 57-8.

6 Wierda JMKH, Proost JH, Schiere S, Hommes FDM. Pharmacokinetics and pharmacokinetic/dynamic relationship of rocuronium bromide in humans. Eur J Anaesthesiol 1994; 11(Suppl): 66-74.

7 Bepan DR. Rocuronium bromide and organ funcrion. Eur J Anaesthesiol 1994; 11(Suppl): 87-91.

8 Cooper RA, Mirakhur RK, Wierda JMKH, Maddineni $V R$. Pharmacokinetics of rocuronium bromide in patients with and without renal failure. Eur J Anaesthesiol 1995; 12(Suppl): $43-4$.

9 van den Broek L, Proost JH, Wierda JMKH. Early and late reversibility of rocuronium bromide. Eur J Anaesthesiol 1994; 11(Suppl): 128-32.

10 Magorian T, Wood P, Caldwell J, Fisher D, et al. The pharmacokinetics and neuromuscular effects of rocuronium bromide in patients with liver disease. Anesth Analg 1995; 80: 754-9.

11 Khalil M, D'Honneur G, Duvaldestin P, Slavov V, De Hys $C$, Gomeni $R$. Pharmacokinetics and pharmacodynamics of rocuronium in patients with cirrhosis. Anesthesiology 1994; 80: 1241-7.

12 Harrison GG. Death attributable to anaesthesia. A 10 year survey (1967-1976). Br J Anaesth 1978; 50: 1041-6.

13 Viby-Mogensen J, Jargensen BC, Ørding H. Residual curarization in the recovery room. Anesthesiology 1979; 50: 539-4l.

14 Miller $R$. How should residual neuromuscular blockade be detected? (Editorial) Anesthesiology 1989; 70 : 379-80.

15 Naguib $M$, Abdulatif $M, A l$-Ghamdi A. Dose-response relationships for edrophonium and neostigmine antagonism of rocuronium bromide (ORG 9426)-induced neuromuscular blockade. Anesthesiology 1993: 79 : 739-45. 